\title{
Review on Satellite Image Classification using Fuzzy Logic
}

\author{
Pranali Shah ${ }^{1}$, Mohammed G. Vayada ${ }^{2}$ \\ ${ }^{1,2}$ Silver Oak College of Engineering and Technology, Ahmedabad, Gujarat, India
}

\begin{abstract}
In present day classification of image plays an important role in engineering and computer vision applications like image processing in remote sensing image. The classification of image is a challenging and important task nowadays. The main problem in satellite image classification is uncertainties in position of object borders and multiple similarities of segments to different classes. To solve this problem fuzzy logic is used, as it efficiently handles uncertainty. This paper shows different technique for image classification and proposed method fuzzy logic is described in detail and shows fuzzy model for detecting water by taking a satellite image example.
\end{abstract}

Keywords: Classification, Fuzzy logic, Image processing, Satellite image, ANN, SVM, Decision tree.

\section{Introduction}

Image processing is used to convert an image into digital form and perform some operations on it, in order to get an enhanced image or to extract some useful information from it. The various purpose of image processing is image sharpening and restoration, image retrieval, image recognition, visualization and measurement of pattern. Image processing is used in remote sensing, biomedical imaging techniques, moving object tracking, intelligent transportation system etc. Classification between the objects is easy task for human but it is difficult task for machines. Classification system basically consists of database that contains predefined patterns that compares with detected object to classify in to proper category.

Image classification is contextual information in image. Contextual means it will mainly focus on relationship of nearby pixels. Image classification is an important and challenging task in various application domains like remote sensing, vehicle navigation, robot navigation, video surveillance and biomedical imaging remote sensing. Image classification process includes different steps like different digital data, pre-processing, feature extraction, selection of training data, decision and classification, classification output, post-processing and accuracy assessment ${ }^{[5]}$.Satellite image is an image of the whole or part of earth taken using artificial satellites. Satellite image plays an important role in showing what cannot be measured or seen. It gives good representation of what is happening at every point in the world. Satellite images provide informative information. The output of classified remotely sensed images will classify different areas from satellite image in form of land, vegetation, water bodies, rock etc ${ }^{[1]}$.

The paper aims to describe proposed method in detail. Section 2 describes the survey done to know the work done and history. Section 3 shows different techniques for image classification. Section 4 shows proposed method in detail. Section 5 shows fuzzy model for detecting water by taking a satellite image example.

\section{Literature Survey}

Four supervised classification techniques such as mahalanobis, maximum likelihood classification, minimum distance and parallelepiped are classified with different time period of satellite images. Comparision of all supervised classification is done with different Landsat satellite images of different time period. ${ }^{[1]}$

Object based image analysis method is used which is also known as image analysis method based on image segment. Initial classification is done through semantic based analysis method. Then the result of initial classification will be modified based on qualitative matching and classification is done using proposed method. ${ }^{[2]}$

In object oriented classification the image is divided into series of image object adopting fuzzy classification to achieve classification and information extraction. The classification is done using object oriented and maximum likelihood classification. Comparisions are made between object oriented and maximum likelihood classification. ${ }^{[3]}$

Proposed method shows how an image can be classified from given large image data base. Artificial neural network and $\mathrm{k}$ nearest neighbour methods are used for classification and comparision is done between them in terms of training data and testing data ${ }^{[4]}$.

3. Different Techniques for Image
Classification


International Journal of Science and Research (IJSR)

ISSN (Online): 2319-7064

Index Copernicus Value (2013): 6.14 $\mid$ Impact Factor (2014): 5.611

\begin{tabular}{|c|c|c|c|}
\hline $\begin{array}{c}\text { Classification } \\
\text { techniques }\end{array}$ & Description & Advantages & disadvantages \\
\hline $\begin{array}{l}\text { Artificial } \\
\text { neural } \\
\text { network }\end{array}$ & $\begin{array}{l}\text { It is an artificial intelligence that will imitates } \\
\text { functions of person's mind and has normal tendency } \\
\text { for storing experimental knowledge. It consists of } \\
\text { sequence of layers and each layer consists of set of } \\
\text { neurones. All neurones of each layer are linked by } \\
\text { weighted connections to all neurones on preceding } \\
\text { and succeeding layers. }\end{array}$ & $\begin{array}{l}\text { It is a non parametric } \\
\text { classifier. Noisy inputs are } \\
\text { handled efficiently. }\end{array}$ & $\begin{array}{l}\text { The training is quiet time } \\
\text { consuming. } \\
\text { It has problem of over fitting. It is } \\
\text { difficult to choose the network } \\
\text { architecture type }\end{array}$ \\
\hline Decision tree & $\begin{array}{l}\text { It calculates class membership by repeatedly dividing } \\
\text { a dataset into similar subsets. It consists of } 3 \text { parts: } \\
\text { partitioning the nodes, find the terminal nodes and } \\
\text { allocation of class label to terminal node. }\end{array}$ & $\begin{array}{l}\text { It handles non parametric } \\
\text { training data efficiently. It } \\
\text { does not require extensive } \\
\text { design and training. }\end{array}$ & $\begin{array}{l}\text { It becomes complex calculation } \\
\text { when various values are } \\
\text { Undecided and various outcomes } \\
\text { are correlated. }\end{array}$ \\
\hline $\begin{array}{l}\text { Support } \\
\text { vector } \\
\text { machine }\end{array}$ & $\begin{array}{l}\text { It builds a hyper plane or set of hyper plane in a high } \\
\text { or infinite dimensional space used for classification. }\end{array}$ & $\begin{array}{l}\text { It reduces complexity. } \\
\text { It eliminates the problem of } \\
\text { over fitting. }\end{array}$ & $\begin{array}{l}\text { Its training is time consuming. } \\
\text { Its structure of algorithm is } \\
\text { difficult to understand }\end{array}$ \\
\hline
\end{tabular}

\section{Fuzzy logic}

Fuzzy logic is a problem solving control system method that lends itself to implementation in system which is ranging from small, simple, embedded micro controllers to large networked multi channel PC or workstation based acquisition and control systems. It can be implemented in software, hardware or a combination of both. It provides a simple way to arrive at a definite conclusion which depends upon noisy, imprecise, inaccurate, or missing input information. In fuzzy classification various stochastic associations are determined to describe characteristics of an image. The various types of stochastic are combined and members of this set of properties are fuzzy in nature. It provides description of different categories of stochastic characteristics which are in similar form ${ }^{[5]}$.Fuzzy logic is used in different areas of applications like management and decision making, process control, operation research, pattern recognition and classification. The major advantage of fuzzy logic is that it provides natural description of problems in linguistic terms and not in terms of relationships between precise numerical value ${ }^{[7]}$.It is user defined function. It has membership function. It efficiently handles uncertainity so more accurate results are obtained. Properties are described by identifying various stochastic relationships. In traditional classification methods each pixel in the image will have an attribute equal to 1 or 0 whether a pixel belongs to a certain class or not. In fuzzy classification instead of using a binary decision making the possibility of each pixel belonging to a specific class is considered and is defined using membership function. A membership function offers membership degree values ranging from 0 to 1 , where 1 means fully belonging to the class and 0 means it does not belongs to the class.

\subsection{Fuzzy sets}

Fuzzy logic mainly starts with the concept of a fuzzy set. A fuzzy set is a set which is a clearly defined boundary without a crisp. It is a set whose elements are having degrees of membership. Its element can be a full member or a partial member. The membership value assigned to an element is not limited to two values i.e. 0 and 1 but can be any value in between. ${ }^{[7]}$

\subsection{MATLAB's Fuzzy Logic Tool Box}

Fuzzy logic tool box is used as precise mathematical model are lacking which will describe behavior of the system. It allows using logic if then rules to describe the behavior of the system. The toolbox is a collection of functions which are built on the MATLAB numeric computing environment and provides tools for creating and editing fuzzy inference systems within the framework of MATLAB.$^{[6]}$ The toolbox provides three categories of tools: A command line functions, a graphical interactive tools, Simulink blocks and examples. Fuzzy logic toolbox allows two types of system building: Fuzzy Inference System (FIS) and adaptive Neuro-fuzzy inference system (ANFIS).

\subsection{Fuzzy inference system}

It is the process of formulating the mapping from a given input to an output using fuzzy logic. The fuzzy inference process mainly involves: membership functions, fuzzy logic operators and if- then rules. There are two types of fuzzy inference systems which can be implemented: Sugeno type and Mamdani type. Mamdani's fuzzy inference method is most common method which is used in fuzzy methodology and it expects the output membership functions to be fuzzy sets. There is a fuzzy set for each output variable which needs defuzzification after the aggregation process. Sugeno type systems is used to model any inference system where the output membership functions are either constant or linear.

\subsection{Membership function}

It is mathematical function that defines the degree of an element's membership in a fuzzy set. The fuzzy logic toolbox includes 11 built in membership function types. ${ }^{[7]}$

\subsection{If then rules}

The knowledge involved in fuzzy reasoning is expressed as: If $x$ is $A$ then $y$ is $B$ where $x$ and $y$ are fuzzy variables and $A, B$ are fuzzy values. If part of the rule " $x$ is $A$ " is called the antecedent or premise while then part of rule " $\mathrm{y}$ is $\mathrm{B}$ " is called consequent or conclusion. ${ }^{[7]}$ 


\section{International Journal of Science and Research (IJSR) \\ ISSN (Online): 2319-7064}

Index Copernicus Value (2013): 6.14 | Impact Factor (2014): 5.611

\section{Results and discussions}

Fig.4 shows satellite image in which water will be classified. Fig. 5 shows how range of RGB is selected.

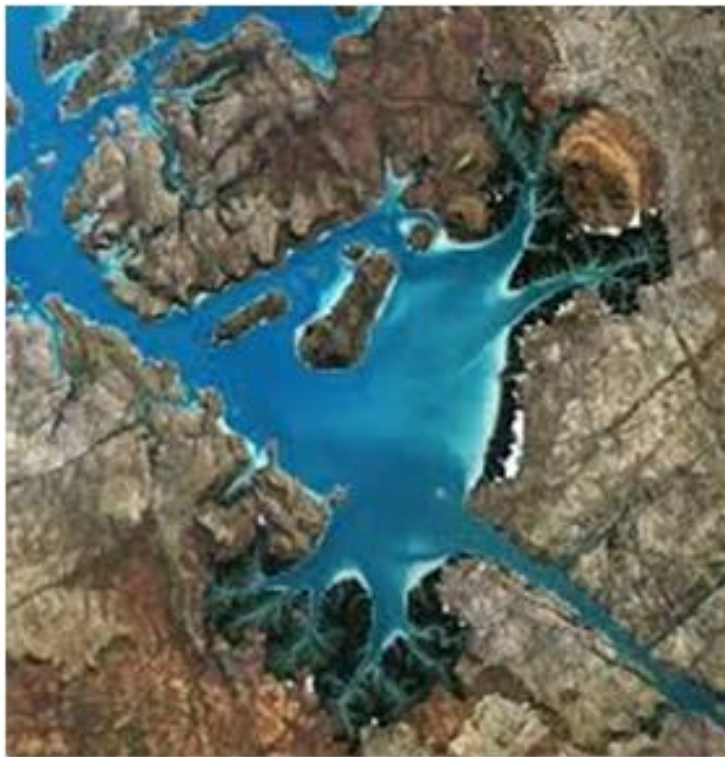

Figure 4: Satellite image

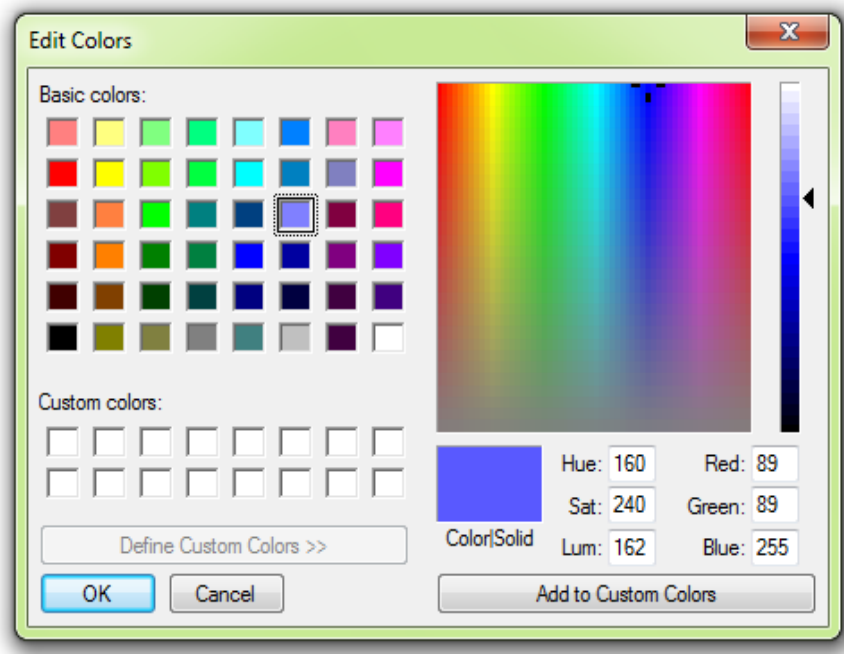

Figure 5: Range

The fuzzy Inference System Editor displays general information about a fuzzy inference system: a simple diagram with the names of each input variable and output variable. In fig. 6 shows the model with three input variable.

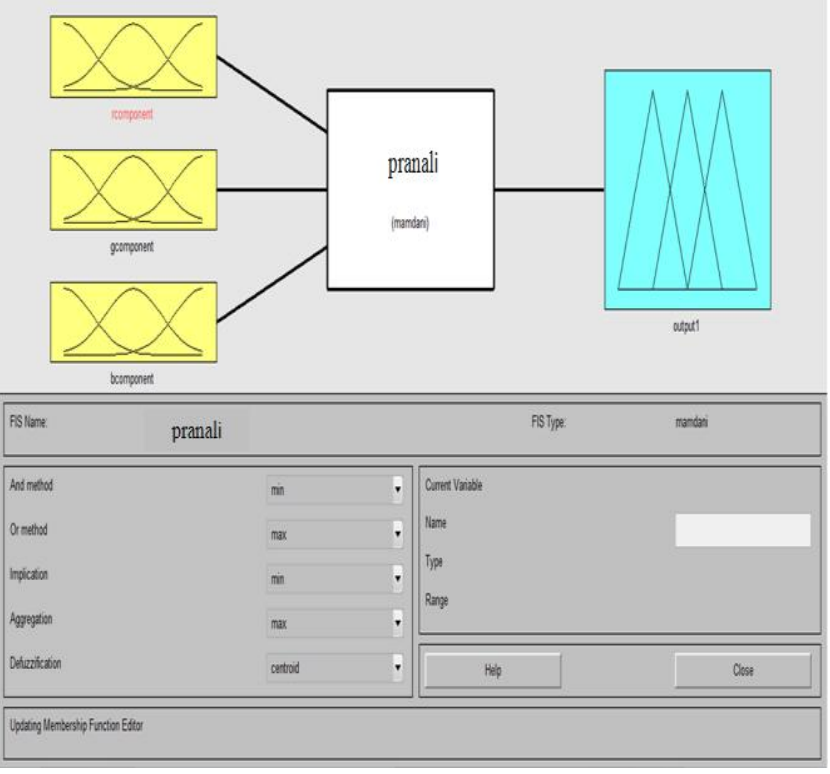

Figure 6: Fuzzy model

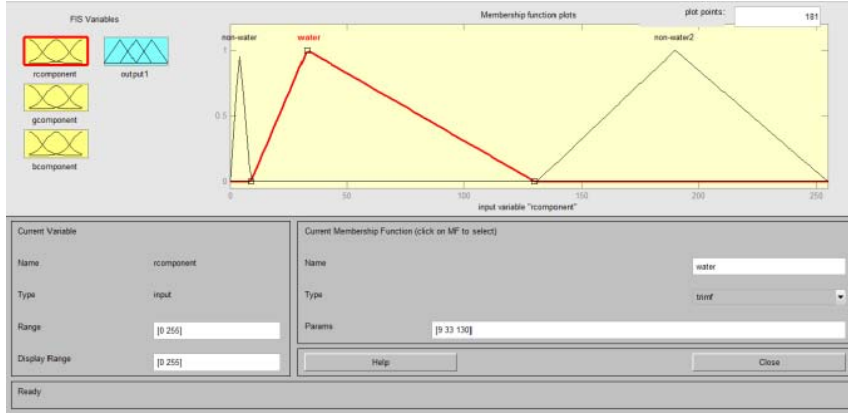

Figure 7: Membership function of red band image

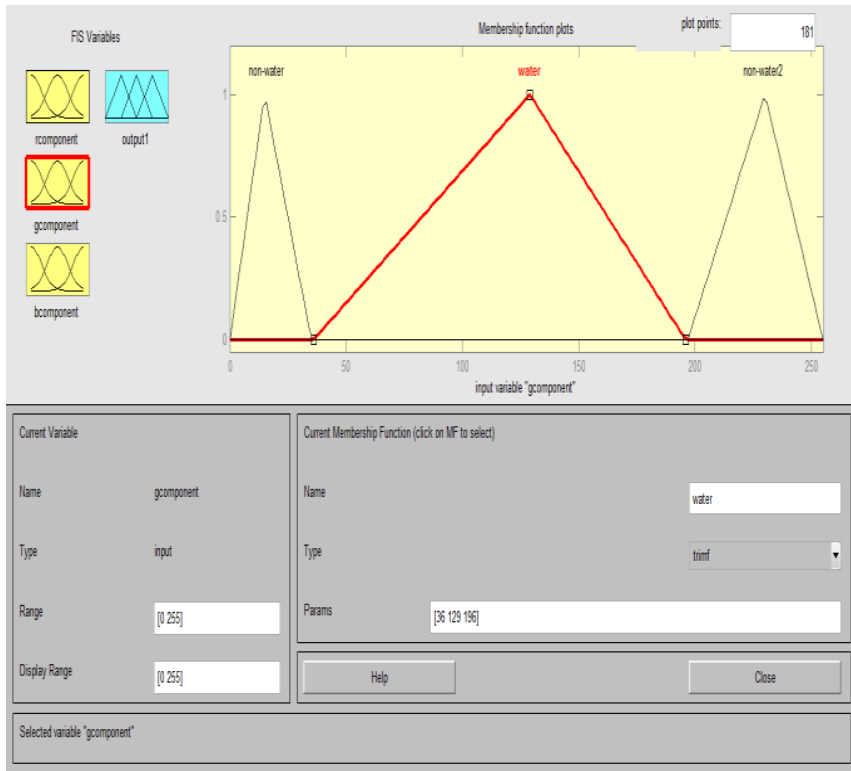

Figure 8: Membership function of green band image 


\section{International Journal of Science and Research (IJSR) \\ ISSN (Online): 2319-7064}

Index Copernicus Value (2013): 6.14 | Impact Factor (2014): 5.611

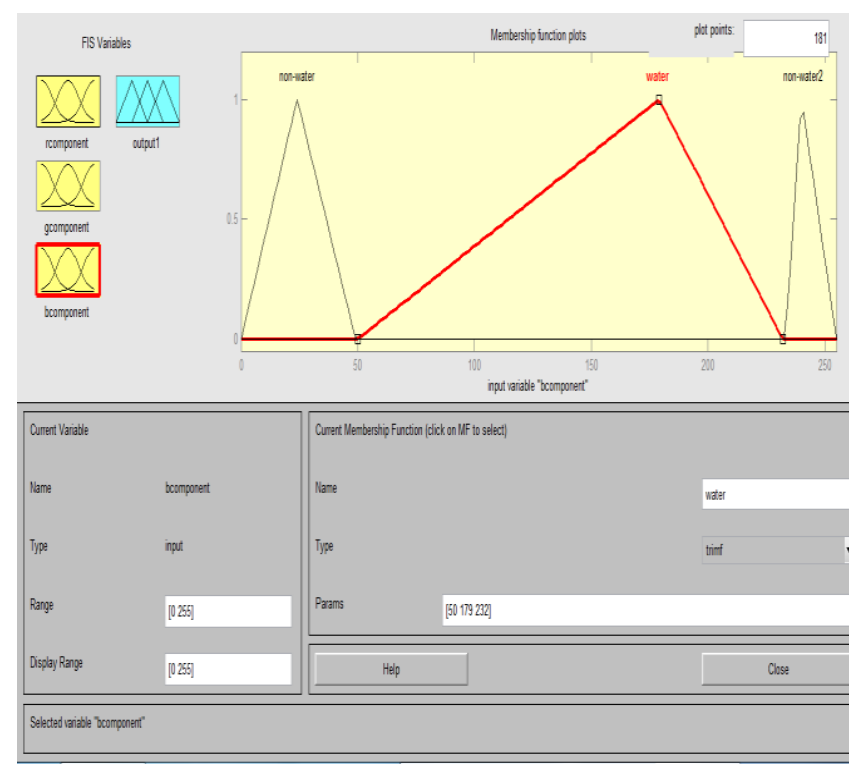

Figure 9: Membership function of blue band image

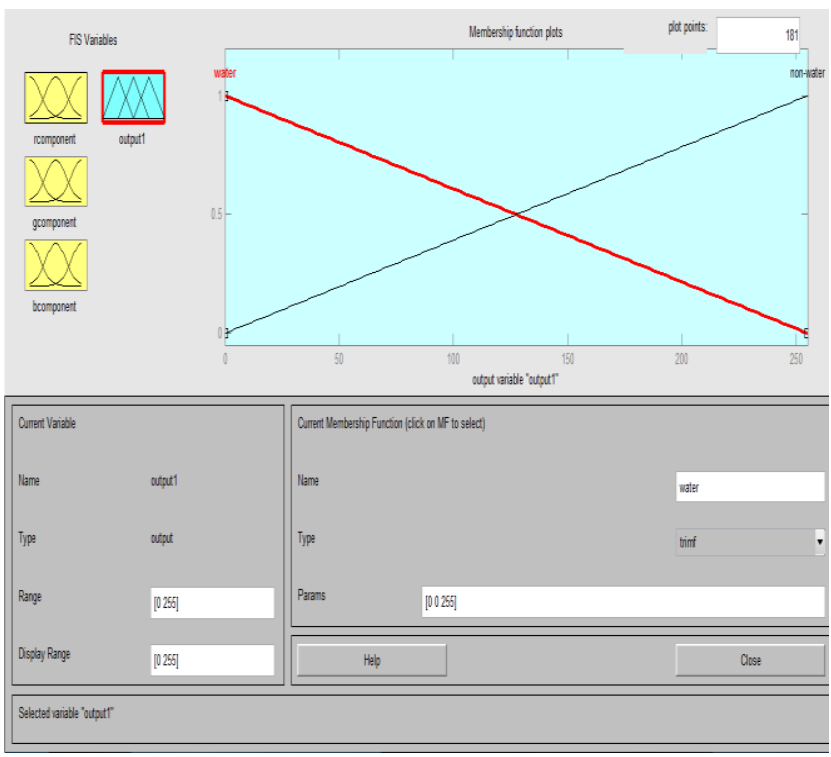

Figure 10: Output

Fig.10 shows that water will be classified in given satellite image.

\section{Conclusion}

Image classification faces many challenges in terms of efficiency this paper shows the different techniques used in image classification, it mainly focuses on the image classification using fuzzy logic and provides detailed description of proposed method. In this paper a Satellite image is taken in which water will be detected using FIS and membership function editor. Similarly classification can be done in different areas for different region.

\section{References}

[1] Pushpendra Singh Sisodia, Vivekanand Tiwari, Anil Kumar. "A Comparative Analysis of Remote Sensing Image Classification Techniques". 978-1-4799-30807/14/\$31.00c 2014 IEEE.
[2] Limin Zhang, Tao Xu, Jianting Zhang, Yingfu Yu. “A Knowledge- based procedure for remote Sensing Image Classification". 978-1-4799-5148-2/14/\$31.00 (C)2014 IEEE.

[3] Chuan Zhang, Yingjun Zhao, Donghui Zhang and Ningbo Zhao. "Application and evaluation of object oriented technology in high resolution remote sensing image classification". 978-1-4577-0860-2/11/\$26.00 (C)2011 IEEE.

[4] Dharmendra Patidar, Nitin Jain, Ashish Parikh. "Performance Analysis of Artificial Neural Network and K Nearest Neighbors Image classification Techniques with Wavelet features". 978-1-4799-36717/36@2014IEEE.

[5] Pooja Kamavisdar, Sonam Saluja, Sonu Agrawal. "A survey on image classification approaches and techniques."International Journal of Advanced Research in Computer and communication engineering Vol. 2, Issue 1, January 2013.

[6] Vini Malik, Aakanksha Gautam, Aditi Sahai, Ambika Jha, Ankita Ramvir Singh. "Satellite Image Classification Using Fuzzy Logic.” International Journal of Recent technology and Engineering Vol 2 may 2013.

[7] MapSoft Ltd 2611000 Belgrade, Serbia and Montenegro "Image classification based on fuzzy logic". The International Archives of the photogrammetry, Remote Sensing and Spatial Information sciences, Vol. 34, Part XXX.

[8] D. Lu and q. weng, "A survey of image classification methods and techniques for improving classification performance" International Journal of Remote Sensing Vol. 28, No. 5, 10 March 2007.

[9] Mather, Paul, and Brandt Tso. "Classification methods for remotely sensed data.” CRC press, 2010.

[10]Lizarazo, Ivan, Elsner, Paul. "Fuzzy segmentation for object-based image classification.” Int. J. Remote Sens. 2009, 30, 1643-1649.

[11]Zhuo, F. "The method of image segmentation in application and analysis of remote sensing [J]. Remote Sensing technology and Application"2006, 21(5):456462.

\section{Author Profile}

Pranali T. Shah, Student of ME (Electronics \& Communication) final year at Gujarat Technological University, Ahmedabad, India from Silver Oak College of Engineering \& Technology.

Mohammed G. Vayada, M.E (Electronics \& Communication) working as Asst professor at Silver Oak College of Engineering \& Technology, has published 9 research papers in various fields like VLSI, Image Processing, Speech Processing, Antenna Designing in International \& National journals, $\mathrm{He}$ has also published book related to Xilinx System Generator. 